\title{
The Laboratory Diagnosis of Autoimmune Encephalitis
}

\section{Review}

Journal of Epilepsy Research pISSN 2233-6249 / eISSN 2233-6257
Received August 25, 2016

Accepted September 16, 2016

Corresponding author: Sang Kun Lee Department of Neurology, Seoul National University College of Medicine, 101 Daehak-ro, Jongno-gu, Seoul 03080, Korea

Tel. +82-2-2072-2923

Fax. +82-2-3672-7553

E-mail; sangkun2923@gmail.com

\author{
Sang Kun Lee, Soon-Tae Lee \\ Department of Neurology, Seoul National University College of Medicine, Seoul, Korea
}

Autoimmune encephalitis is a group of encephalitis syndromes that cause altered mentality, memory decline, or seizures in association with the presence of serum and cerebrospinal fluid (CSF) autoantibodies (auto-Abs). An early diagnosis enables early treatments. The detection of auto-Abs is a confirmatory diagnosis. Tissue-based assay, cell-based immunoassay, and immunoblotting are used to detect various autoantibodies. The CSF test for the presence of antibodies is important because it is more sensitive and reflects disease activity in many autoimmune encephalitis, although antibody tests can be negative even in the presence of autoimmune encephalitis. EEG is often abnormal, but nonspecific. A unilateral or bilateral medial temporal T2 high signal is a common finding in MRI. Fludeoxyglucose-positron emission tomography is sometimes useful for diagnosis in patients with normal MRI. (2016;6:45-52)

Key words: Autoimmune encephalitis, Autoantibody, Laboratory diagnosis, Imaging, EEG

\section{History and categories of autoimmune encephalitis}

Autoimmune encephalitis is a group of syndromes that occur in association with autoantibodies (auto-Abs), which are presumed to be responsible, or partly responsible, for the development of epilepsy and encephalitis. ${ }^{1}$ Many series of patients with autoimmune encephalitis involve B-cell-mediated autoimmunity. However, some syn- dromes may also involve T-cell-mediated immunity. ${ }^{2-4}$ They are also responsible for a small, but significant, number of cases of epilepsy.

In 1980, intravenous immunoglobulin therapy was introduced to treat autoimmune diseases, and from 1980 to 2000, many classical onconeuronal autoimmune antibody-associated syndromes were reported, including anti-Yo, -Hu, -amphiphysin, -CRMP5 (collapsin response mediator protein 5), and -Ma paraneoplastic auto-Abs (Fig. 1). ${ }^{5}$ Since 2000 , many new autoimmune synaptic auto-Abs have

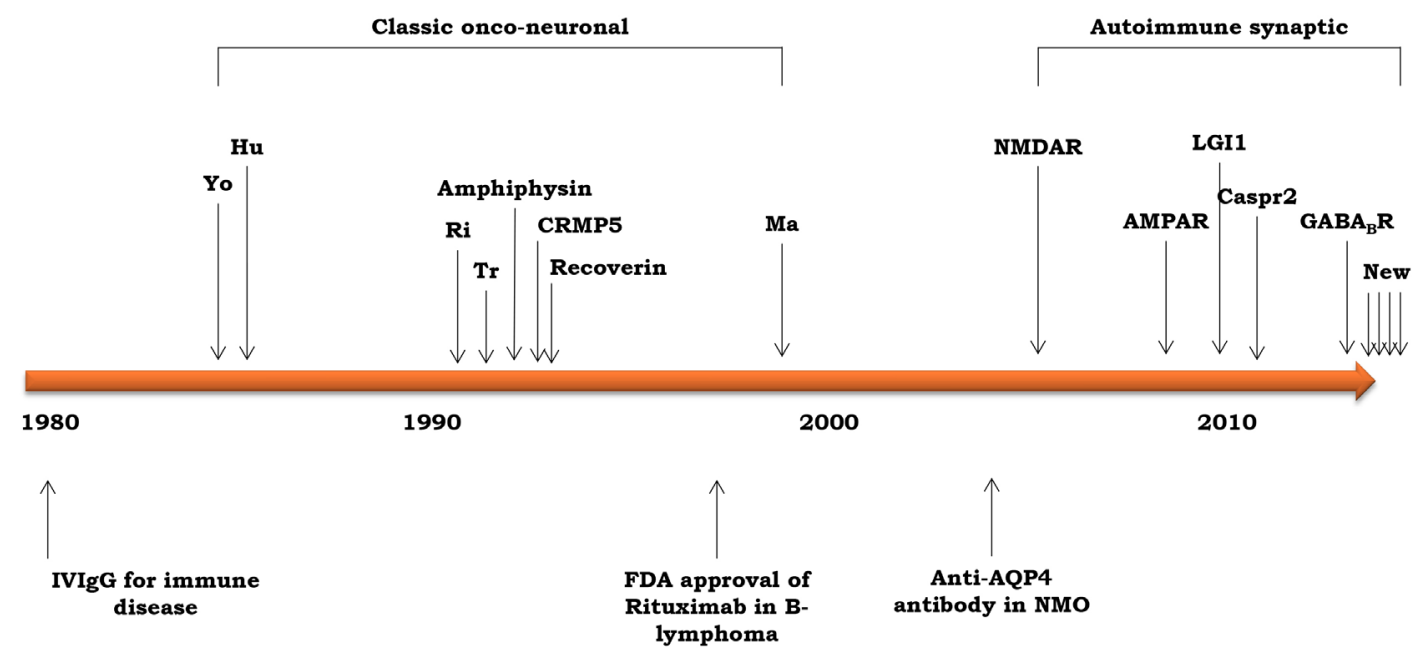

Figure 1. The discovery of antibodies of autoimmune encephalitis along the time axis. 
Table 1. The various diagnostic approaches used in autoimmune encephalitis

\begin{tabular}{|c|c|c|}
\hline Clues & Advantages & Disadvantages \\
\hline Syndrome-based criteria & $\begin{array}{l}\text { - Enable early immunotherapy } \\
\text { - Useful for inclusion criteria of clinical studies }\end{array}$ & $\begin{array}{l}\text { - Incorrect } \\
\text { - Not helpful for differential diagnosis } \\
\text { - Can lead to over-immunotherapy }\end{array}$ \\
\hline Response to immunotherapy & - Useful in retrospective case analysis & $\begin{array}{l}\text { - Many patients with AE do not respond to } \\
1^{\text {st }} \text {-line immunotherapy } \\
\text { - Not useful for initial decision }\end{array}$ \\
\hline $\begin{array}{l}\text { Clinicians' "gut feeling" based on } \\
\text { clinical course, MRI, and CSF test }\end{array}$ & - Case-specific approaches & $\begin{array}{l}\text { - Requires experience } \\
\text { - Incorrect }\end{array}$ \\
\hline Antibody test & $\begin{array}{l}\text { - Confirmatory } \\
\text { - Determines comorbidities, tumors, long-term } \\
\text { treatment, and prognosis }\end{array}$ & $\begin{array}{l}\text { - Half of AE cases are antibody negative } \\
\text { - Time and availability for antibody tests } \\
\text { - False positive or asymptomatic antibodies }\end{array}$ \\
\hline
\end{tabular}

$A E$, autoimmune encephalitis

been discovered, such as the anti-NMDA receptor (NMDAR, N-methyl-D-aspartate receptor), anti-AMPAR ( $\alpha$-amino-3-hydroxy-5-methyl-4-isoxazolepropionic acid receptor), anti-LGI1 (Leucine-rich glioma inactivated 1), anti-Caspr2 (contactin-associated protein-like 2), and anti-GABAB receptor ( $\gamma$-aminobutyric acid class $B$ receptor) receptor Abs. ${ }^{6}$

The various types of autoimmune encephalitis antibodies can be categorized into three groups: ${ }^{3}$ intracellular paraneoplastic $A b$, cell-surface or synaptic $A b$, and with $A b$ of unclear significance. Intracellular paraneoplastic antibody is frequently associated with systemic tumors (in more than $90 \%$ of cases). These patients are less responsive to immunotherapy because the antibody causes neuronal damages. Cell-surface or synaptic Ab is variably associated with systemic tumors, and patients with these $A b$ are more responsive to immunotherapy. The classical example of encephalitis with Ab of unclear significance is Hashimoto's encephalitis, which is positive for the thyroid peroxidase $A b$, although this $A b$ is not directly pathogenic.

\section{Diagnosis of autoimmune encephalitis}

Diagnostic criteria for autoimmune encephalitis were proposed recently. ${ }^{7}$ For the diagnosis of definite autoimmune limbic encephalitis, all four of the following criteria have to be met: subacute onset, bilateral brain abnormalities on T2-weighted fluid-attenuated inversion recovery (FLAIR) MRI highly restricted to the medial temporal lobes, cerebrospinal fluid (CSF) pleocytosis or EEG with epileptic or slow-wave activity on the temporal lobe, and reasonable exclusion of alternative causes. Although detection of auto-Abs is the best diagnostic method for autoimmune encephalitis, there are many Ab-neg-
Table 2. Common cancers associated with autoimmune antibodies

\begin{tabular}{ll}
\hline Antibody & \multicolumn{1}{c}{ Common tumor } \\
\hline Hu & SCLC, neuroendocrine tumors \\
Yo & Ovary, breast cancer \\
CV2/CRMP5 & SCLC, thymoma \\
Ri & Breast, gynecologic cancer, SCLC \\
Ma2 & Testicular, breast cancer, lung cancer, \\
Amphiphysin & Stomach cancer \\
Recoverin & Breast cancer, SCLC \\
NMDA receptor & SCLC, NSCLC \\
LGI1 & Ovarian or mediastinal teratoma \\
Caspr2 & Thymoma, lung cancer, \\
GABA B receptor & Thymoma \\
GABA A receptor & SCLC \\
AMPA receptor & Rare \\
\hline
\end{tabular}

SCLC, small cell lung cancer; NSCLC, non-small cell lung cancer

ative probable autoimmune encephalitis cases. Because early application of immunotherapy is essential for the treatment of autoimmune encephalitis, early suspicion based on clinical findings is important. There are several methods for the diagnosis of autoimmune encephalitis (Table 1). Because each has advantages and disadvantages, we have to select appropriate diagnostic approaches in specific situations. The laboratory diagnosis of autoimmune encephalitis consists in the detection of auto-Abs, EEG, MRI, functional neuroimaging, and work-up for systemic tumors.

\section{Work-up for systemic tumors}

Many cases of autoimmune encephalitis are associated with systemic tumors (Table 2) ${ }^{8,9}$ Therefore, suitable methods should be applied to detect these tumors (Table 3). 
Table 3. Recommended tests for cancer screening in patients with autoimmune encephalitis

\begin{tabular}{ll}
\hline Category & \multicolumn{1}{c}{ Examination } \\
\hline All patients & $\begin{array}{c}\text { Chest and abdomen-pelvis CT } \\
\text { Pelvis MRI to detect any tiny ovarian } \\
\text { teratoma } \\
\text { Gynecological exam, and } \\
\text { mammography/breast ultrasound } \\
\text { Men }\end{array}$ \\
$\begin{array}{l}\text { Urologic exam and ultrasonography } \\
\text { Wears with } \mathrm{Ab}\end{array}$ & Whole-body PET \\
\hline
\end{tabular}

The expression of target antigens by the tumor tissue itself usually contributes to the genesis of auto-Abs, especially in many paraneoplastic autoimmune encephalitis series. ${ }^{10,11}$ The detection of systemic tumors is very important, not only because systemic tumors can be fatal in cases of delayed treatments, but also because the removal of the tumor can facilitate the recovery from autoimmune encephalitis. ${ }^{19,12,13}$ Sometimes, the size of the cancer or tumor is too small to allow its detection when the initial neurological symptoms and signs appear. In these cases, even though the initial screening for tumors is negative, repeated follow-up assessments are necessary.

\section{Detection of auto-Abs}

Although about half of all autoimmune encephalitis series are Ab-negative cases, the detection of auto-Abs is a confirmatory diagnostic test. Three basic research techniques are used for this purpose: tissue-based assay, cell-based assay, and immunoprecipitation.

The tissue-based assay is a screening method. In this method, mouse-brain tissue sections, such as hippocampal and cerebellar sections, are stained with the patient's serum or CSF using an indirect immunofluorescence technique. This enables the detection even of unknown Abs, as well as the established Ab (Fig. 2). ${ }^{14}$

In the diagnosis of specific autoimmune encephalitis, the cell-based immunoassay is used for the detection of cell-surface or synaptic Abs, and immunoblotting is used for the detection of intracellular paraneoplastic Abs. The cell-based immunoassay is a new technology of autoimmune diagnostics. ${ }^{15}$ Four main procedures are involved in this method: the insertion of DNA encoding the target antigens into a plasmid, transfection of this plasmid into vector cells, reaction of vector cells with the patient's serum or CSF, and detection of specific Abs via indirect immunofluorescence (Fig. 3).

For the detection of classical intracellular onconeuronal Abs, the immunoblotting technique is used. Immunoblotting is the method that uses Abs to detect a specific protein from a mixture of several un-

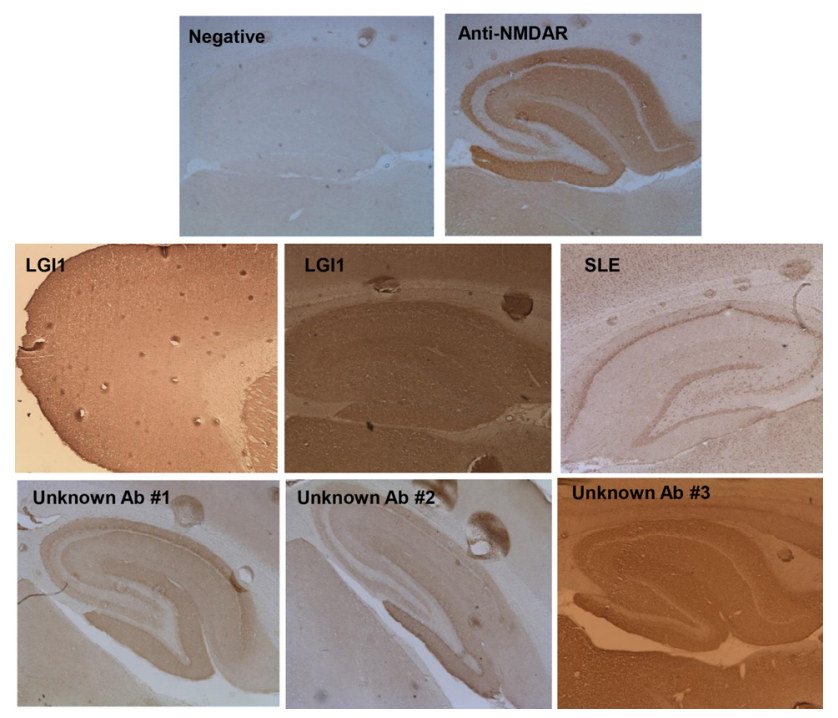

Figure 2. The tissue based assay. Mouse brain tissue sections such hippocampus and cerebellum are stained with the patient's serum or CSF by indirect immunofluorescence technique.
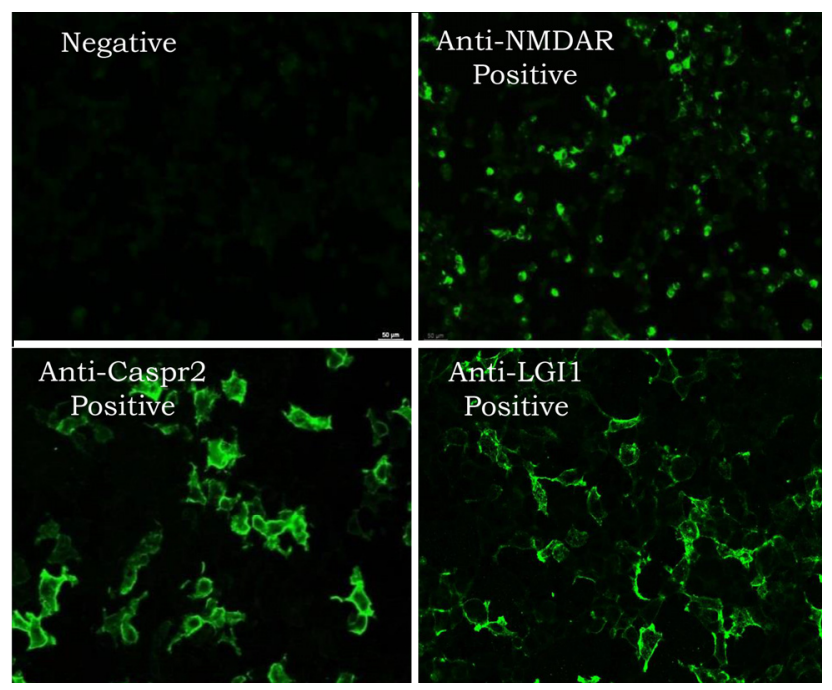

Figure 3. Cell-based immunoassay. The procedures are insertion of DNA cording for the target antigens into a plasmid, transfection of this plasmid into vector cells (neuronal cells), reaction of neuronal vector cells with the patient's serum or CSF, and detection of monospecific Ab by indirect immunofluorescence.

related proteins. The application of this technique in antibody diagnosis involves several steps, including the separation of proteins via electrophoresis, the transfer of the proteins onto a membrane, and the overlay of primary (patients' sample) and secondary Abs onto the membrane, followed by detection using enzymes or radioisotopes. ${ }^{16}$

The diagnostic steps used in our hospital are summarized in Fig. 4. The screening test is performed using the tissue-based assay in all patients with suspected autoimmune encephalitis. For the detection 


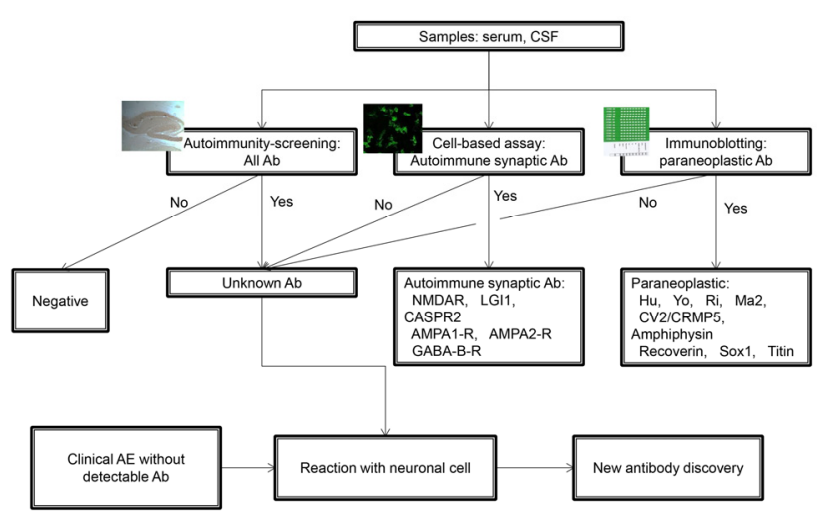

Figure 4. The diagnostic steps to detect known and unknown antibodies.
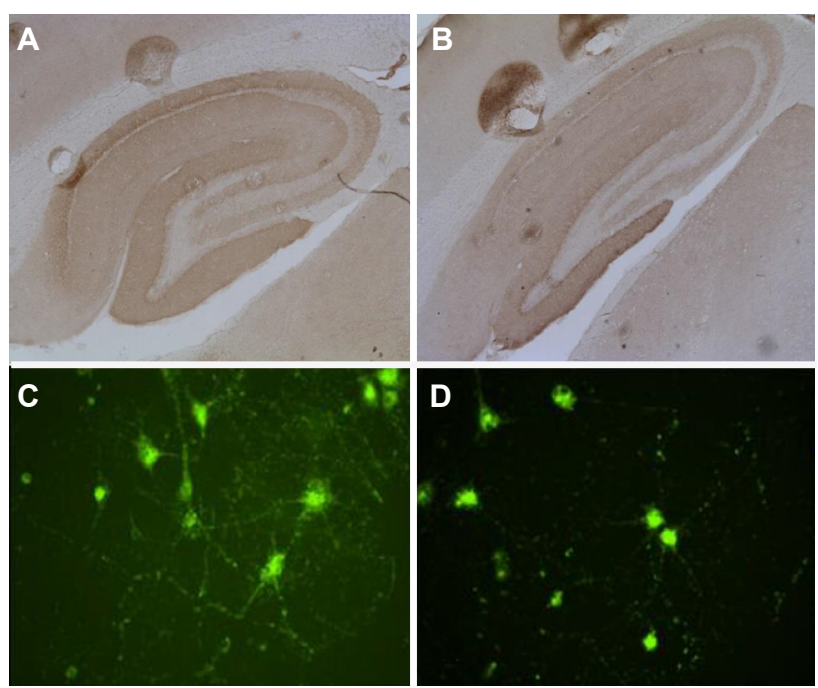

Figure 5. The detection of novel antibodies. The detection of unknown antibodies by tissue-based assay (A and B), interaction of antibodies with neuronal cells, and confirming the presence of unknown antibodies (C and D).

\section{A}

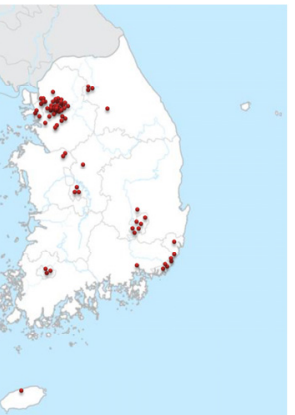

B Autoimmune synaptic

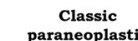

$n=130$

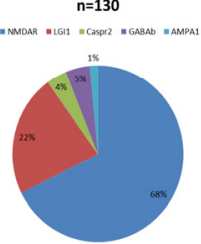

$n=88$

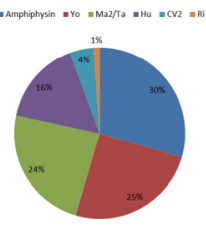

Figure 6. KASPER (Korea Autoimmune Synaptic and Paraneoplastic Encephalitis Registry). Samples were collected from 72 nationwide hospitals (A). The most common synaptic autoimmune encephalitis was NMDAR Ab (68\%) followed by LGI1 Ab encephalitis (22\%). The common onco-neuronal paraneoplatic encephalitis series were Amphiphysin, Yo, and $\mathrm{Ma} 2 / \mathrm{Ta}$ (B).

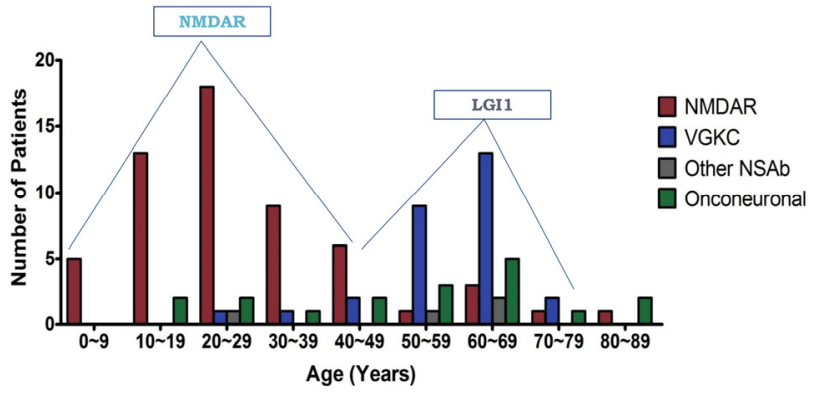

Figure 7. Two age peaks in autoimmune encephalitis. NMDAR encephalitis had the highest peak at the third decades and LGI1 at the 7th decades.

of synaptic and intracellular Abs, the cell-based immunoassay and immunoblotting are used, respectively. In the case of the detection of an unknown Ab in the tissue-based assay (Fig. 5A, B), we perform confirmative tests staining cultured neuronal cells with the patients' sample (Fig. 5C, D). Further immunoprecipitation via liquid chromatography and mass spectrometry enables the identification of a novel specific antigen. The generation of overexpressing cell lines allows the creation of a new system for the diagnosis of the presence of novel Ab.

We created the Korea Autoimmune Synaptic and Paraneoplastic Encephalitis Registry (KASPER). From June 2012 to 2015, more than 2500 samples were collected from 72 hospitals nationwide (Fig. 6A). ${ }^{17,18}$ The positive rate for autoimmune encephalitis was $8.6 \%$. We found more than 10 cases with possible novel antibodies. The most common synaptic autoimmune encephalitis was that associated with the anti-NMDAR Ab (68\%), followed by anti-LGI1 Ab encephalitis (22\%). Anti-amphiphysin, anti-Yo, and anti-Ma2/Ta encephalitis were common onconeuronal paraneoplastic encephalitis series (Fig. 6B). We observed two age peaks in the occurrence of autoimmune encephalitis (Fig. 7). Anti-NMDAR encephalitis had the highest peak in the third decade, and anti-LGI1 encephalitis had a peak at the seventh decade. ${ }^{18}$

\section{CSF findings}

CSF findings were abnormal in most cases, ${ }^{19,20}$ albeit nonspecific. ${ }^{21}$ Lymphocytic pleocytosis and increased CSF protein was the commonest finding. An oligoclonal band was also found in a quarter of the patients.

Testing for the presence of the anti-NMDAR Ab in CSF is important. The sensitivity of anti-NMDAR Ab testing is higher in CSF compared with serum. Among the patients who were identified as having Ab in CSF, 85.6\% had Abs in serum for the anti-NMDAR Ab, 
whereas $100 \%$ of the patients with a positive serum for this Ab also had positive CSF samples. ${ }^{22}$ The serum was negative for the antiNMDAR Ab in $14 \%$ of the patients with a positive Ab in the CSF. ${ }^{13}$ This was explained by the frequent intrathecal synthesis of Abs in anti-NMDAR encephalitis. The proportion of CD19(+) B cells was reported to be greater than $10 \%$, which is significantly higher than that observed in noninflammatory neurological disorders. ${ }^{23}$ The conversion from a high to a low titer and rapidly declining titer in the patients correlated with good outcome and lower relapse rates. ${ }^{22} \mathrm{~A}$ high auto-Ab titer in the CSF and serum was related with a poor outcome.

\section{Antibody-negative autoimmune encephalitis}

The Ab test can be negative even in the presence of autoimmune encephalitis. Some explanations are available for these negative $A b$ tests, even with the application of tissue-based analyses. These include antigen denaturation during tissue fixation, false-negative results caused by a small amount of $\mathrm{Ab}$, differences between human and mouse epitopes, and the presence of T-cell-dominant autoimmune encephalitis. The existence of Ab-negative autoimmune encephalitis was supported by the finding that $44 \%$ of patients that are rituximab responders have autoimmune encephalitis without detectable Abs. ${ }^{24}$

In contrast, the positive Ab test does not always imply the presence of pathogenic $A b$. Some patients with small cell lung cancer and the anti-Hu Ab are asymptomatic. ${ }^{25}$ The presence of the anti-TPO Ab in Hashimoto's thyroiditis is not relevant to the disease process. $^{26}$

The Ab against the voltage-gated potassium channel can be present in Miller-Fisher syndrome and Bickerstaff encephalitis. ${ }^{27}$ The anti-NMDAR Ab can be present in multiple sclerosis and neuromyelitis optica. Some patients were identified as having demyelinating disorders in addition to anti-NMDAR encephalitis. ${ }^{28-30}$ In some cases, it is difficult to determine whether these patients have two concurrent neurological conditions or there is a false-positive Ab test.

\section{EEG}

EEG was abnormal in $90 \%$ of cases of anti-NMDAR encephalitis. ${ }^{19}$ However, these findings were nonspecific. Nonconvulsive status epilepticus (NCSE) patterns, periodic lateralized epileptiform discharges, or nonspecific slowing were observed. In some cases, continuous EEG is necessary to detect a subclinical ictal rhythm or NCSE pattern. In anti-NMDAR encephalitis, it may be difficult to differentiate NCSE from continuous orofacial dyskinesia without EEG. Generalized rhythmic delta activity with superimposed fast activity (extreme delta brush) is present in some patients with anti-NMDAR encephalitis. ${ }^{31}$ The presence of an extreme delta brush was suggestive of more prolonged hospitalization. However, other EEG findings failed to differentiate autoimmune encephalitis with a different etiology. 32

\section{MRI}

Unilateral or bilateral medial temporal $\mathrm{T} 2$ high signals with an extrahippocampal cortical or subcortical lesion are common findings in onconeuronal autoimmune encephalitis (Fig. 8A). ${ }^{33-35}$ These medial temporal high signals or swelling may be followed by progressive hippocampal atrophy, together with a chronic course. ${ }^{36}$

In anti-NMDAR encephalitis, MRI abnormalities were found only in 20\%-50\% of patients. ${ }^{13,37,38} \mathrm{MRI}$ is frequently normal or mild even in patients with anti-NMDAR encephalitis who are in a comatose state. The lesion may involve various areas of the brain. ${ }^{19,39-41}$ In anti-VGKC encephalitis, MRI did not differentiate anti-LGI1 encephalitis from anti-CASPR2 Ab encephalitis. ${ }^{42-44}$ Unilateral or bilateral medial temporal T2 or FLAIR high-signal changes were typically found in anti-LGI1 encephalitis (in more than 70\% of cases). ${ }^{45-47}$ In some cases, these changes were accompanied by basal ganglia signal changes. Hippocampal atrophy usually progressed along with disease progression in the absence of proper treatment. ${ }^{44,46,48}$ Unilateral or bilateral medial temporal $\mathrm{T} 2$ high signals were also found in the majority of anti-GABAB Ab encephalitis (Fig. 8B). ${ }^{49-51}$ On rare occasions, brainstem abnormalities were found in anti-GABAB Ab encephalitis with brainstem involvement. ${ }^{52,53}$
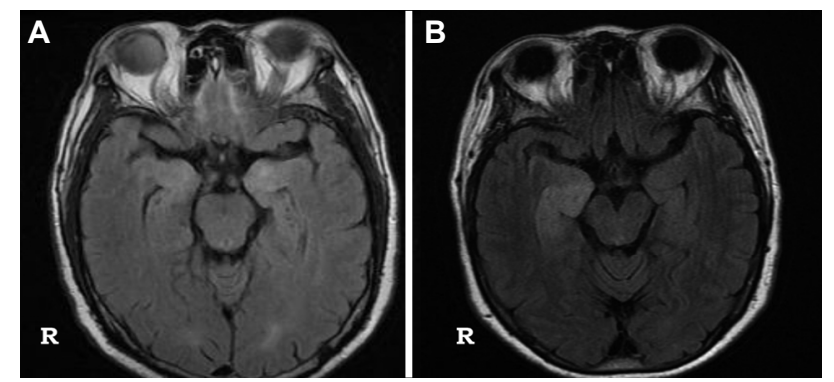

Figure 8. Common findings of autoimmune encephalitis. Bilateral (A) or unilateral medial temporal T2 high signals (B). 

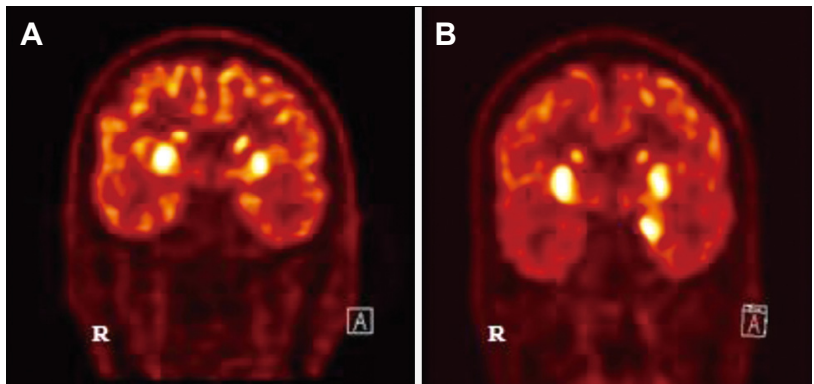

Figure 9. Typical FDG-PET findings of LGI1 encephalitis. Bilateral basal ganglia hypermetabolism (A) with medial temporal hypermetabolsim (B).

\section{FDG-PET}

FDG-PET scan is useful in the detection of abnormalities, even in patients with a normal MRI. It usually shows medial temporal hypoor hypermetabolic changes in limbic encephalitis. ${ }^{54,55}$ FDG-PET abnormalities in anti-NMDAR encephalitis were found at various brain sites, such as the frontal, temporal, and occipital lobes, brainstem, and cerebellum. ${ }^{37,39,41,56}$ The findings ranged from focal hypermetabolism to diffuse hypometabolism. . $739,41,56-58$ FDG-PET in anti-LGI1 encephalitis frequently showed basal ganglia and medial temporal hypermetabolism (Fig. 9). ${ }^{47,60}$

\section{Conclusions}

Autoimmune encephalitis is a group of epilepsy and encephalitis syndromes that are associated with serum and CSF auto-Abs. The detection of auto-Abs is a confirmatory diagnosis. A tissue-based assay is used as a screening method, and a cell-based immunoassay is applied for the detection of synaptic Abs, whereas immunoblotting is used for the detection of intracellular paraneoplastic Abs. The Ab tests using both CSF and serum are necessary and CSF sometimes reflects disease activity. The Ab test can be negative even in the presence of autoimmune encephalitis. Efforts aimed at detecting new auto-Abs are needed. EEG is nonspecific. A unilateral or bilateral medial temporal T2 high signal is a common finding in MRI. FDG-PET is sometimes useful as a diagnostic tool in patients with a normal MRI, and exhibit medial temporal hypo- or hypermetabolism and basal ganglia hypermetabolism in anti-LGI1 encephalitis.

\section{References}

1. Lancaster $E$. The diagnosis and treatment of autoimmune encephalitis.
J Clin Neurol 2016;12:1-13.

2. Bernal F, Graus F, Pifarré A, Saiz A, Benyahia B, Ribalta T. Immunohistochemical analysis of anti-Hu-associated paraneoplastic encephalomyelitis. Acta Neuropathol 2002;103:509-15.

3. Lancaster E, Dalmau J. Neuronal autoantigens-pathogenesis, associated disorders and antibody testing. Nat Rev Neuro/ 2012;8:380-90.

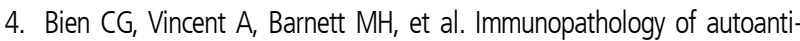
body-associated encephalitides: clues for pathogenesis. Brain 2012;135(Pt 5):1622-38.

5. Darnell RB, Posner JB. Paraneoplastic Syndromes. New York: Oxford, 2011.

6. Lancaster E, Martinez-Hernandez E, Dalmau J. Encephalitis and antibodies to synaptic and neuronal cell surface proteins. Neurology 2011;77:179-89.

7. Graus F, Titulaer MJ, Balu R, et al. A clinical approach to diagnosis of autoimmune encephalitis. Lancet Neurol 2016;15:391-404.

8. Rosenfeld MR, Dalmau J. Diagnosis and management of paraneoplastic neurological disorders. Curr Treat Options Oncol 2013;14:528-38.

9. Dalmau J, Rosenfeld MR. Autoimmune encephalitis update. Neuro Oncol 2014;16:771-8.

10. Dalmau J, Fumeaux HM, Rosenblum MK, Graus F, Posner JB. Detection of the anti-Hu antibody in specific regions of the nervous system and tumor from patients with paraneoplastic encephalomyelitis/sensory neuropathy. Neurology 1991;41:1757-64.

11. Dalmau J, Tüzün $E$, Wu $H Y$, et al. Paraneoplastic anti-N-methyl-d-aspartate receptor encephalitis associated with ovarian teratoma. Ann Neurol 2007;61:25-36.

12. Hughes EG, Peng $X$, Gleichman A, et al. Cellular and synaptic mechanisms of anti-NMDA receptor encephalitis. J Neurosci 2010;30:5866-75.

13. Titulaer MJ, McCracken L, Gabilondo I, et al. Treatment and prognostic factors for long-term outcome in patients with anti-NMDA receptor encephalitis: an observational cohort study. Lancet Neurol 2013;12:156-65.

14. Hoftberger R. Neuroimmunology: an expanding frontier in autoimmunity. Fron Immunol 2015;6:206.

15. Probst C, Saschenbrecker S, Stoecker W, Komorowski L. Anti-neuronal autoantibodies: current diagnostic challenges. Mult Scler Relat Disord 2014;3:303-20.

16. Magi B, Liberatori S. Immunoblotting techniques. Methods Mol Biol 2005;295:227-54.

17. Sunwoo JS, Lee ST, Byun Jl, et al. Clinical manifestations of patients with CASPR2 antibodies. J Neuroimmunol 2015;281:17-22.

18. Byun Jl, Lee ST, Jung KH, et al. Prevalence of antineuronal antibodies in patients with encephalopathy of unknown etiology: Data from a nationwide registry from Korea. J Neuroimmuno/ 2016;293:34-8.

19. Dalmau J, Gleichman AJ, Hughes EG, et al. Anti-NMDA-receptor encephalitis: case series and analysis of the effects of antibodies. Lancet Neurol 2008;7:1091-8.

20. Wang $R$, Guan $H Z$, Ren HT, Wang W, Hong Z, Zhou D. CSF findings 
in patients with anti- $N$-methyl-d-aspartate receptor encephalitis. Seizure 2015;29:137-42.

21. Lim JA, Lee $S T$, Jung $K H$, et al. Anti- $N$-methyl-d-aspartate receptor encephalitis in Korea: clinical features, treatment, and outcome. J Clin Neurol 2014;10:157-61.

22. Gresa-Arribas N, Titulaer MJ, Torrents A, et al. Antibody titers at diagnosis and during follow-up of anti-NMDA receptor encephalitis: a retrospective study. Lancet Neurol 2014;13:167-77.

23. Dale RC, Pillai S, Brilot F. Cerebrospinal fluid CD19(+) B-cell expansion in $N$-methyl-d-aspartate receptor encephalitis. Dev Med Child Neurol 2013;55:191-3.

24. Lee WJ, Lee ST, Byun Jl, et al. Rituximab treatment for autoimmune limbic encephalitis in an institutional cohort. Neurology 2016;86:1683-91.

25. Dalmau J, Furneaux HM, Gralla RJ, Kris MG, Posner JB. Detection of the anti-Hu antibody in the serum of patients with small cell lung cancer-a quantitative western blot analysis. Ann Neurol 1990;27:544-52.

26. Kirshner HS. Hashimoto's encephalopathy: a brief review. Curr Neurol Neurosci Rep 2014:14:476.

27. Tüzün $E$, Kürtüncü $M$, Lang $B$, et al. Bickerstaff's encephalitis and Miller Fisher syndrome associated with voltage-gated potassium channel and novel anti-neuronal antibodies. Eur J Neurol 2010;17:1304-7.

28. Kruer MC, Koch TK, Bourdette DN, et al. NMDA receptor encephalitis mimicking seronegative neuromyelitis optica. Neurology 2010;74:1473-5.

29. Lekoubou A, Viaccoz A, Didelot $A$, et al. Anti- $N$-methyl-d-aspartate receptor encephalitis with acute disseminated encephalomyelitis-like MRI features. Eur I Neurol 2012;19:e16-7.

30. Pennington C1, Livingstone S, Santosh C, Razvi S. N-methyl D-aspartate receptor antibody encephalitis associated with myelitis. I Neurol Sci 2012;317:151-3.

31. Schmitt SE, Pargeon K, Frechette ES, Hirsch $\sqcup$, Dalmau J, Friedman D. Extreme delta brush: a unique EEG pattern in adults with anti-NMDA receptor encephalitis. Neurology 2012:79:1094-100.

32. Baysal-Kirac $L$, Tüzün $E$, Altindag $E$, et al. Are there any specific EEG findings in autoimmune epilepsies? Clin EEG Neurosci 2016;47:224-34.

33. Gultekin SH, Rosenfeld MR, Voltz R, Eichen J, Posner JB, Dalmau J. Paraneoplastic limbic encephalitis: neurological symptoms, immunological findings and tumor association in 50 patients. Brain 2000;123:1481-94.

34. Lawn ND, Westmoreland BF, Kiely MJ, Lennon VA, Vernino S. Clinical, magnetic resonance imaging, and electroencephalographic findings in paraneoplastic limbic encephalitis. Mayo Clin Proc 2003;78:1363-8.

35. Urbach $H$, Soeder BM, Jeub M, Klockgether T, Meyer B, Bien CG. Serial MRI of limbic encephalitis. Neuroradiology 2006;48:380-6.

36. Bartsch T. The hippocampus in neurological disease. In: Bartsch T, ed. The clinical neurobiology of the hippocampus. Oxford: Oxford University Press, 2012;200-23.

37. Irani SR, Bera K, Waters $P$, et al. N-methyl-d-aspartate antibody encephalitis: temporal progression of clinical and paraclinical observations in a predominantly non-paraneoplastic disorder of both sexes. Brain
2010;133(Pt 6):1655-67.

38. Dalmau J, Lancaster E, Martinez-Hernandez E, Rosenfeld MR, Balice-Gordon R. Clinical experience and laboratory investigations in patients with anti-NMDAR encephalitis. Lancet Neurol 2011;10:63-74.

39. Wegner $F$, Wilke $F$, Raab $P$, et al. Anti-leucine rich glioma inactivated 1 protein and anti-N-methyl-D-aspartate receptor encephalitis show distinct patterns of brain glucose metabolism in 18F-fluoro-2-deoxy-d-glucose positron emission tomography. BMC Neurol 2014;14:136.

40. Tojo K, Nitta K, Ishii W, et al. A young man with anti-NMDAR encephalitis following Guillain-Barré syndrome. Case Rep Neurol 2011;3:7-13.

41. Vitaliani R, Mason W, Ances B, Zwerdling T, Jiang Z, Dalmau J. Paraneoplastic encephalitis, psychiatric symptoms, and hypoventilation in ovarian teratoma. Ann Neurol 2005;58:594-604.

42. Vincent A, Buckley C, Scott JM, et al. Potassium channel antibody-associated encephalopathy: a potentially immunotherapy-responsive form of limbic encephalitis. Brain 2004;127(Pt 3):701-12.

43. Ances BM, Vitaliani R, Taylor RA, et al. Treatment-responsive limbic encephalitis identified by neuropil antibodies: MRI and PET correlates. Brain 2005:128(Pt 8):1764-77.

44. Kotsenas AL, Watson RE, Pittock CJ, et al. MRI findings in autoimmune voltage-gated potassium channel complex encephalitis with seizures: one potential etiology for mesial temporal sclerosis. ANNR Am J Neuroradiol 2014;35:84-9.

45. Lai M, Huijbers MGM, Lancaster $E$, et al. Investigation of LGI1 as the antigen in limbic encephalitis previously attributed to potassium channels: a case series. Lancet Neurol 2010;9:776-85.

46. Irani SR, Stagg CJ, Schott JM, et al. Faciobrachial dystonic seizures: the influence of immunotherapy on seizure control and preventions of cognitive impairment in a broadening phenotype. Brain 2013;136:3151-62.

47. Shin YW, Lee ST, Shin JW, et al. VGKC-complex/LGI1-antibody encephalitis: clinical manifestations and response to immunotherapy. J Neuroimmunol 2013;265:75-81.

48. Andrade DM, Tai P, Dalmau J, Wennberg R. Tonic seizure: A diagnostic due of anti-LGI1 encephalitis? Neurology 2011;76:1355-7.

49. Lancaster $E$, Lai $M$, Peng $X$, et al. Antibodies to $G A B A(B)$ receptor in limbic encephalitis with seizures: case series and characterization of the antigen. Lancet Neurol 2010;9:67-76.

50. Boronat A, Gelfand JM, Gresa-Arribas N, et al. Encephalitis and antibodies to dipeptidyl-peptidase-like protein-6, a subunit of Kv4.2 potassium channels. Ann Neurol 2013;73:120-8.

51. Kim TJ, Lee ST, Shin JW, et al. Clinical manifestations and outcomes of the treatment of patients with $G A B A B$ encephalitis. I Neuroimmunol 2014;270:45-50.

52. Jarius $S$, Steinmeyer $F$, Knobel $A$, et al. GABAB receptor antibodies in paraneoplastic cerebellar ataxia. J Neuroimmuno/ 2013;256:94-6.

53. Mundiyanapurath $S$, Jarius $S$, Probst C, Stöcker W, Wildemann B, Bösel J. GABA-B-receptor antibodies in paraneoplastic brainstem encephalitis. J Neuroimmuno/ 2013;259:88-91.

54. Scheid R, Lincke T, Voltz R, et al. Serial 18-fluoro-2-deoxy-d-glucose 
positron emission tomography and magnetic resonance imaging of paraneoplastic limbic encephalitis. Arch Neurol 2004;61:1785-9.

55. Basu S, Alavi A. Role of FDG-PET in the clinical management of paraneoplastic neurological syndrome: detection of the underlying malignancy and the brain PET-MRI correlates. Mol Imaging Biol 2008;10:131-7.

56. Leypoldt F, Buchert R, Kleiter I, et al. Fluorodeoxyglucose positron emission tomography in anti- $N$-methyl-d-aspartate receptor encephalitis: distinct pattern of disease. J Neurol Neurosurg Psychiatry 2012;83:681-6.

57. Fisher RE, Patel NR, Lai EC, Schulz PE. Two different 18F-FDG brain
PET metabolic patterns in autoimmune limbic encephalitis. Clin Nud Med 2012;37:e213-8.

58. Baumgartner A, Rauer S, Mader I, Meyer PT. Cerebral FDG-PET and MRI findings in autoimmune limbic encephalitis: correlation with autoantibody types. J Neurol 2013;260:2744-53.

59. Maqbool M, Oleske DA, Huq AH, Salman BA, Khodabakhsh $K$, Chugani HT. Novel FDG-PET findings in anti-NMDA receptor encephalitis: a case based report. J Child Neurol 2011;26:1325-8.

60. Irani SR, Michell AW, Lang B, et al. Faciobrachial dystonic seizures precede LGI1 antibody limbic encephalitis. Ann Neurol 2011;69:892-900. 